\title{
Genotypes and drug susceptibility of Mycobacterium tuberculosis Isolates in Shihezi, Xinjiang Province, China
}

\author{
Juan Zhang ${ }^{1}$, Ligu Mi ${ }^{1}$, Yuanzhi Wang ${ }^{1}$, Peizhi Liư ${ }^{2}$, Haiyan Liang ${ }^{1}$, Yi Huang ${ }^{1}$, Bing LV ${ }^{3}$ and Li Yuan ${ }^{1 *}$
}

\begin{abstract}
Background: Tuberculosis (TB) remains a major global health problem. To investigate the genotypes of Mycobacterium tuberculosis (MTB) and the distribution of Beijing family strains, molecular epidemiology technologies have been used widely.

Methods: From June 2010 to June 2011, 55 M. tuberculosis isolates from patients with pulmonary TB were studied by Beijing family-specific PCR (detection of the deletion of region of difference 105 [RD105]), and mycobacterial interspersed repetitive units variable number tandem repeat (MIRU-VNTR) analysis. Twenty-four MIRU-VNTR loci defined the genotypes and clustering characteristics of the local strains. All strains were subjected to a drug susceptibility test (DST) by the proportion method on Lowenstein-Jensen (LJ) culture media.

Results: Fifty-five clinical isolates of MTB were collected. Beijing family strains represented $85.5 \%$ of the isolates studied. Using 24 loci MIRU-VNTR typing categorized the strains into eight gene groups, 46 genotypes, and seven clusters. $83.6 \%(46 / 55)$ of the isolates belonged to the largest gene group. Thirty-six isolates (65.5\%) were susceptible, nineteen (34.5\%) were resistant to at least one drug, seven (12.8\%) were Multidrug-Resistant Tuberculosis (MDR TB), and two (3.6\%) were extremely drug-resistant tuberculosis (XDR-TB).

Conclusion: The results showed there were obvious polymorphisms of VNTRs of MTB clinical strains. Beijing family strains of MTB were predominant in the Shihezi region of Xinjiang province. There was no correlation between the drug-resistance and Beijing family strains of MTB. It is necessary to strengthen the monitoring, treatment, and management of drug-resistance TB in Shihezi region, Xinjiang.
\end{abstract}

Keywords: Mycobacterium tuberculosis, Genotype, Drug susceptibility test, Xinjiang

\section{Background}

Tuberculosis (TB) is an infectious disease caused by the bacillus Mycobacterium tuberculosis (MTB). TB remains a major public health threat worldwide. China has occupied second place, behind India, among the top five high-burden countries for the last decade (http://www. who.int/tb/en). In 2010, there were 8.8 million (range, 8.5-9.2 million) incident cases of $T B$, and 1.1 million (range, 0.9-1.2 million) deaths from TB among HIVnegative people [1]. Genotyping methods have been extensively used to analyze the recent transmission dynamics of $M T B$. Different PCR-based genotyping approaches

\footnotetext{
* Correspondence: yuanli832000@sina.com

'Department of Pathogenic Biology and Immunology, School of Medicine,

Shi Hezi University, Shihezi, People's Republic of China
}

targeting the variable number of tandem repeats (VNTR) have been developed, based on the mycobacterial interspersed repetitive units (MIRU) [2,3], which are considered a good alternative to the reference method and have proven to be faster and easier to perform. The discriminatory power of MIRU-VNTR analysis is related to the number of loci. MIRU-VNTR genotyping is performed by amplifying a panel of 12,15 , or 24 loci [4]. More recently, a set of 24 MIRU-VNTR loci was reported to have greater discriminatory power than the original 12 loci system and may exceed that of restriction fragment length polymorphism (RFLP) when combined with spoligotyping $[5,6]$. The MIRU-VNTR method is a reliable and reproducible typing method with high discriminatory power for studying the $M T B$ population structure in different countries [7-12].
Full list of author information is available at the end of the article




The MTB Beijing family, first identified in 1995 in Beijing, China, is ubiquitously and significantly prevalent in certain world regions, e.g., East Asia [13]. Members of the MTB Beijing family are a major concern because of their high prevalence in tuberculosis patients and their high rate of multi-drug resistance [14]. Several studies have observed that the Beijing family $M T B$ strains exhibits important pathogenic features that might be associated with drug resistant $T B$ in China [15-17]. As the prevalence of drug resistant clones of $M T B$ varies from one area to another, studies of the geographical distribution of resistant clones are useful for understanding the epidemiological characteristics of TB. Spoligotyping usually determines the genotype of a Beijing strain of MTB. However, this technique requires special equipment and is time-consuming. A previous study demonstrated a high the correlation between Spoligotyping and the RD105 deletion for the identification of the Beijing family genotype [17]. The simple and rapid new method, the RDl05 deletion test, was used to identify the Beijing family instead of Spoligotyping [18]. RD105 deletions have previously been reported to be Beijing family strainsspecific. One large sequence polymorphism, the (LSP)RD105 genomic deletion, was observed in all Beijing family strains and thus serves as a useful marker for the identification of this family of strains [19]. The RD105 deletion test was performed to identify Beijing family isolates in different countries [20].

Xinjiang is a province on the Northwestern coast of China. The incidence of $T B$ in Xinjiang is estimated at 463 cases per 100,000 persons per year. The prevalence of drug-resistant $T B$ in Xinjiang Province is higher than the average level in China. Xinjiang is a multiethnic area, being home to 55 ethnicities. The most numerous are the Uygur (46.06\%), followed by Han (39.33\%), and Kazakh (7.08\%). In the northern regions of Xinjiang, most of the population is Han, but in the southern regions, about $85 \%$ of the population is Uygur, and only $8 \%$ of the population is Han. Shihezi region is in northern Xinjiang and has area of 456.8 square kilometers and a population of 630,000 ; $95 \%$ of the population is Han. In 2008, the network epidemic of Shihezi reported $991 \mathrm{tu}-$ berculosis cases and prevalence of $152.15 / 100,000$. TB ranks as the second statutory infectious disease in Shihezi [21].

The main goal of this study was to genotype MTB strains circulating in the Shihezi region of Xinjiang Province using MIRU-VNTR-24 locus analysis and to understand the genetic diversity of Beijing and non-Beijing isolates by the RD105 deletion test. We also sought to the determine drug susceptibility patterns of the $M T B$ isolates and whether the drug resistance of epidemic $T B$ are directly related to the spread of Beijing family strains.

\section{Methods}

\section{Mycobacterial specimens}

This study included $M$. tuberculosis samples isolated between June 2010 and June 2011 from Shihezi in Xinjiang Province. Standard questionnaires were used to collect classical epidemiology data. Information was obtained on sex, age, place of birth, recent positive smear test, previous history of $T B$, and current address.

\section{Strain isolation and drug susceptibility test}

The sputum samples were cultured and isolated on Lowenstein-Jensen (LJ) culture media. Four first-line anti-TB drugs (isoniazid [INH], rifampicin [RFP], streptomycin [SM], and ethambutol [EMB]) and seven secondline anti-TB drugs (ofloxacin [Ofx], Capreomycin $[\mathrm{Cm}]$, Amikacin [Am], Kanamycin [KM], P-aminosalicylicacid [PAS], Ethionamide [Eto], and Cycloserine [Cs]) were incorporated into LJ medium, at the following concentrations: INH0, $2 \mu \mathrm{g} / \mathrm{ml}$; RFP, $40.0 \mu \mathrm{g} / \mathrm{ml}$; SM, $4.0 \mu \mathrm{g} / \mathrm{ml}$; EMB, $2.0 \mu \mathrm{g} / \mathrm{ml} ; \mathrm{Ofx}, 2.0 \mu \mathrm{g} / \mathrm{ml} ; \mathrm{Cm}, 40.0 \mu \mathrm{g} / \mathrm{ml} ; \mathrm{Km}$, $30.0 \mu \mathrm{g} / \mathrm{ml} ;$ Am, $40.0 \mu \mathrm{g} / \mathrm{ml} ;$ PAS, $1.0 \mu \mathrm{g} / \mathrm{ml}$; Eto, $40.0 \mu \mathrm{g} / \mathrm{ml}$; and Cs, $40.0 \mu \mathrm{g} / \mathrm{m}$, and used to detect the drug-resistance of the $M T B$ by the proportion method. Strain were scored as resistant to a specific drug, or were defined as sensitive thief their growth rate was $<1 \%$ compared to the control. Strain isolation, identification, and drug susceptibility tests (DST) were performed at the Ministry of Education Key Laboratory of Xinjiang Endemic and Ethnic Disease.

\section{Genomic DNA extraction and molecular identification of M. tuberculosis isolates}

Mycobacterial genomic DNA was extracted from mycobacterial colonies growing on LJ medium. Scraped colonies were dissolved in 200-300 $\mu$ l of distilled water and inactivated at $85^{\circ} \mathrm{C}$ for $30 \mathrm{~min}$, before being centrifuged at $8000 \mathrm{r} / \mathrm{min}$ for $5 \mathrm{~min}$. The pellets were resuspended in $300 \mu \mathrm{l}$ of TE ( $\mathrm{pH} \mathrm{8.3),} \mathrm{boiled} \mathrm{for} 30 \mathrm{~min}$, and centrifuged at $10,000 \mathrm{r} / \mathrm{min}$ for $5 \mathrm{~min}$. Supernatants were collected and stored at $-20^{\circ} \mathrm{C}$ until further use [22].

Molecular identification of the mycobacterial isolates was performed using PCR amplification of the $16 \mathrm{~S}$ rRNA gene and MTP40 gene [23]. The PCR mixture consisted of $0.2 \mu \mathrm{g}$ DNA template, $3 \mu$ l buffer, $4 \mu \mathrm{l}$ $10 \mathrm{mM}$ deoxynucleoside triphosphates, $1 \mu \mathrm{l}$ of each primer $(10 \mathrm{pmol} / \mu \mathrm{l})$, and $1 \mu \mathrm{l}$ DNA Taq polymerase. The amplification cycle was $5 \mathrm{~min}$ at $95^{\circ} \mathrm{C}$; followed by 30 cycles of $40 \mathrm{~s}$ at $95^{\circ} \mathrm{C}, 50 \mathrm{~s}$ at $65^{\circ} \mathrm{C}$, and $40 \mathrm{~s}$ at $72^{\circ} \mathrm{C}$; with a final $10 \mathrm{~min}$ at $72^{\circ} \mathrm{C}$. PCR products were analyzed on a $2 \%$ agarose gel against a 100 -bp DNA ladder.

\section{Genotyping by MIRU-VNTR PCR}

MIRU-VNTR genotyping was performed by amplifying the 24 MIRU-VNTR loci as described previously in a 
technical guide [24]. The 24 MIRU-VNTR genetic loci consisted of ten original MIRU-VNTR loci; six loci of exact tandem repeats (ETRs: ETR-A, -B, -C, -D, -E and -F), five Mtub loci (Mtub4, 21, 30, 38, and 39), and three Queen's University of Belfast (QUBs) loci (QUB$11 \mathrm{~b},-26$, and 4156c). Primers were as described by Supply et al. [25]. For each reaction, DNA from M. tuberculosis $H 37 R v$ was used as a positive control, and sterile water was used as a negative control. PCR products were electrophoretically separated on $2 \%$ agarose gels, using a 100-bp DNA ladder as size markers. From the gel images, the corresponding MIRU-VNTR bands were interpreted as copy numbers based on the reference table in the Supply 2005 protocol [24]. The copy number at each locus was calculated using the Quantity 1 gel imaging system.

\section{Beijing Family strains analysis}

The identification of Beijing Family strains was performed by detecting deletions in region of difference 105 (RD105) by PCR [18]. Each PCR mixture was prepared in a volume of $15 \mu \mathrm{l}$ containing $50 \mathrm{ng}$ of DNA, $1 \mathrm{U}$ of Taq polymerase, a $0.2 \mathrm{mM}$ concentration of each deoxynucleoside triphosphate (dNTP), and $0.2 \mu \mathrm{M}$ (each) primer. The amplification cycle was $5 \mathrm{~min}$ at $94^{\circ} \mathrm{C}$; followed by 30 cycles of $30 \mathrm{~s}$ at $94^{\circ} \mathrm{C}, 30 \mathrm{~s}$ at $62^{\circ} \mathrm{C}$, and $45 \mathrm{~s}$ at $72^{\circ} \mathrm{C}$; with a final step for $10 \mathrm{~min}$ at $72^{\circ} \mathrm{C}$. PCR products were electrophoretically separated on $2 \%$ agarose gels.

\section{Results}

\section{Patient characteristics}

Ninety sputum specimens from patients with pulmonary $T B$ were collected from June 2010 to June 2011. All of the pulmonary $T B$ patients were Han Chinese. Among 90 patients, $30(33.3 \%)$ specimens were either culture negative or had culture contamination and were excluded. In addition, another five specimens (5.5\%) were excluded because their cultures were mycobacteria other than $T B$ (MOTT). Therefore, 55 culture positive specimens were used for this study.

Of the 55 patients, 20 were new $T B$ cases and 35 were previously treated patients. The mean age of the patients was $47.21 \mathrm{yr}( \pm 2.26)$. There were 38 males $(69.1 \%)$ and 17 females (30.9\%).

\section{MIRU-VNTR genotyping}

Fifty-five $M T B$ isolates were genotyped and 46 different VNTR genotypes were detected. Thirty nine strains (70.9\%) were unique and 16 strains (29.1\%) could be grouped into seven clusters, each including 2-3 strains (Figure 1). Two main clusters which contained 3 (18.7\%) and 3 (18.7\%) strains showed 4. 2435233252633 3454443862 and 42435233251733345
4443752 VNTR profiles, respectively. The isolates were divided into eight groups based on phylogenetic clustering and genotypic characteristics. Groups I to VIII contained 2, 2, 1,1,1,46,1 and 1 isolates, respectively (Table 1). All the clustered isolates were in group VI. In this study, H37Rv separated into a group (Figure 1).

\section{Epidemic of Beijing family strains in Shihezi of Xinjiang Province}

During the study period, $55 \mathrm{M}$. tuberculosis isolates were identified using molecular methods. We used the RD105 deletion test instead of spoligotyping, and found that 47 of the 55 isolates (85.5\%) were of the Beijing family genotype, while eight (24.5\%) were non-Beijing family strains.

\section{Characteristics of the clustered isolates}

Among the 47 Beijing family isolates, 45 (95.7\%) were in group VI and the remaining two isolates were in groups $\mathrm{V}$ and VII. This suggested that the Beijing family isolates distributed mainly in group VI. Sixteen isolates (16/47) were clusters, and were all Beijing family isolates. In contrast, none of the eight non-Beijing family isolates were clustered (Table 2).

\section{Drug susceptibility patterns of the MTB isolates}

The $55 M T B$ strains isolated from the sputum samples of $T B$ patients were subjected to a drug susceptibility test. Drug susceptibility with the four first-line antituberculosis and the seven second-line anti-tuberculosis drugs was examined to determine the association between drug resistance patterns and genotype.

Thirty-six isolates (65.5\%) were susceptible to all eleven drugs; $19(34.5 \%)$ were resistant to at least one drug; seven (12.8\%) were $M D R-T B$ strains, which were resistant to at least INH and RIF, the two most powerful anti- tuberculosis drugs; two (3.6\%) were XDR-TB, defined as $M D R T B$ with further resistance for any quinolones and to $>1$ of the three classes of second-line drugs $(\mathrm{Cm}, \mathrm{Am}$, or $\mathrm{Km})[26]$. We examined the distribution of drug resistance between Beijing and non-Beijing strains. Among the seven $M D R-T B$ isolates, five (10.6\%, $5 / 47$ ) isolates were Beijing family strains, and two $(0.25 \%, 2 / 8)$ were non-Beijing family strains. The rates of $M D R-T B$ among Beijing and non-Beijing family strains were not statistically different $(\mathrm{P}=0.386)$. Among the Beijing family strains, $36.2 \%(n=17)$ were resistant to any drug; among the non-Beijing family strains, $2.5 \%$ $(\mathrm{n}=2)$ were resistant to any drug (Table 2).

Of the 55 patients, 20 (36.4\%) were new $T B$ cases and $35(63.6 \%)$ were previously treated patients. Among the four $M D R-T B$ patients, all had been previously treated, while among the 51 patients with non-MDR-TB, 31 patients $(60.8 \%)$ had been previously treated. However, 
Table 1 MTB characteristics in the eight subgroups

\begin{tabular}{|c|c|c|c|c|c|c|c|c|c|c|}
\hline Isolate characteristic & Total no. of isolates & & & No & (\%) of iso & ates by su & group & & & $P$ value \\
\hline & & $I(n=2)$ & $\|(n=2)$ & III $(n=1)$ & $\mathrm{IV}(\mathrm{n}=1)$ & $V(n=1)$ & VI (n-46) & $\mathrm{VII}(n=1)$ & VIIII $(n=1)$ & \\
\hline Beijing strain & 47 & 0 & 0 & 0 & 0 & 1 & 45 & 1 & 0 & $<0.0001$ \\
\hline Clustered & 16 & 0 & 0 & 0 & 0 & 0 & 16 & 0 & 0 & 0.731 \\
\hline
\end{tabular}

$\mathrm{n}$, number of isolates in the subgroup. 
Table 2 MTB characteristics between Beijing and nonBeijing family strains

\begin{tabular}{llll}
\hline Characteristic & $\begin{array}{l}\text { Total no. } \\
\text { of isolates } \\
(n=55)\end{array}$ & $\begin{array}{l}\text { No. of isolates } \\
\end{array}$ & $\begin{array}{l}\text { Beijing }(n=47) \\
\text { non-Beijing }(n=8)\end{array}$ \\
\hline
\end{tabular}

Resistance

\begin{tabular}{lrrr}
\hline $\mathrm{NH}$ & 8 & 7 & 1 \\
\hline RFP & 5 & 4 & 1 \\
\hline SM & 12 & 11 & 1
\end{tabular}

\begin{tabular}{lccc}
\hline SM & 12 & 11 & 1 \\
\hline EMB & 6 & 6 & 0 \\
\hline
\end{tabular}

\begin{tabular}{llll}
\hline PAS & 3 & 3 & 0 \\
\hline KM & 1 & 1 & 0 \\
\hline
\end{tabular}

\begin{tabular}{llll}
\hline Eto & 2 & 2 & 0
\end{tabular}

\begin{tabular}{llll}
\hline Cs & 2 & 2 & 0 \\
\hline$C M$ & 2 & 1 & 1
\end{tabular}

\begin{tabular}{llll}
\hline CM & 2 & 1 & 1 \\
\hline Am & 1 & 1 & 0 \\
\hline Ofx & 4 & 3 & 1
\end{tabular}

\begin{tabular}{lrrrl}
\hline Any drug-resistance & 19 & 17 & 2 & $0.429^{*}$ \\
\hline MDR & 7 & 5 & 2 & $0.386^{*}$ \\
\hline XDR & 2 & 2 & 0 & $1^{*}$ \\
\hline Susceptibility & 36 & 30 & 6 & $0.429^{*}$ \\
\hline Clustered & 16 & 16 & 0 & $0.113^{*}$ \\
\hline
\end{tabular}

*Value by Fisher's exact test.

there was no association of $M D R-T B$ cases with either new cases or previously treated cases, as shown in Table 3.

\section{Discussion}

Recent advances in molecular technology, such as RD105 deletion and MIRU-VNTR typing, have provided powerful tools for analyzing MTB genotype and transmission patterns, and should prove invaluable for developing effective infection-control policies.

The RDl05 deletions, which can identify the Beijing Family strains, are very valuable molecular markers. In this study, we found that $85.5 \%$ of $M T B$ isolates in the Shihezi region were Beijing family strains. In the previous study, the prevalence of Beijing family strains were

Table 3 MTB characteristics between new cases and previously treated cases

\begin{tabular}{lcccc}
\hline Type & $\begin{array}{c}\text { Total } \\
\mathbf{n = 5 5}\end{array}$ & $\begin{array}{l}\text { New cases } \\
\mathbf{n = 2 0}\end{array}$ & $\begin{array}{l}\text { Previously treated } \\
\text { cases } \mathbf{n = 3 5}\end{array}$ & P value \\
\hline Susceptible & 36 & 12 & 24 & $0.361^{*}$ \\
\hline Any drug-resistance & 19 & 8 & 11 & $0.361^{*}$ \\
\hline MDR & 7 & 0 & 7 & $0.154^{*}$ \\
\hline XDR & 2 & 0 & 2 & $0.264^{*}$ \\
\hline Beijing family & 47 & 16 & 31 & $0.216^{*}$ \\
\hline Clustered & 16 & 5 & 11 & $0.427^{*}$ \\
\hline
\end{tabular}

*Value by Fisher's exact test. different in various regions of China, e.g., $80 \%$ to $90 \%$ in Beijing, 67\% in Ningxia, 89\% in Shanghai, 70\% in Zhejiang, $91.5 \%$ in Tianjin, $55.3 \%$ in Guangxi, $80.4 \%$ in Jiangsu, and $89.5 \%$ in Heilongjiang [12]. Thus, the Beijing family strains were prevalent in China. The association of drug resistance and the Beijing family strains has become a research hotspot. However, results obtained differ. These strains may have a particular propensity for acquiring drug resistance [27]. In our study, the statistical analysis showed that there was no difference between the Beijing and non-Beijing family strains in terms of their drug resistance patterns, indicating that the Beijing family was less likely to be associated with the high prevalence of drug resistance in Shihezi region.

In this study, general resistance to at least one drug and MDR were all higher than the resistance rate observed in 2008 [28]. The presence of two XDR-TB cases $(3.6 \%)$ was another important discovery, and it is the first report of $X D R-T B$ cases in Xinjiang. Worldwide, $X D R-T B$ cases have been reported in 45 countries [29]. In China, a survey of resistance to tuberculosis showed that the rate of $X D R-T B$ was $0.68 \%$ in $2007-2008$ [30]. Therefore, we should pay more attention to $M D R-T B$ and $X D R-T B$ to control tuberculosis.

The MIRU-VNTR method has been used in molecular epidemiology studies, and it is adequate for tracking recent transmission and distinguishing relapses and reinfections [9]. In addition to its high discriminatory power, MIRU typing is simple to perform, has a high throughput, and is highly reproducible with a short turnaround time. MIRU types are represented in digital format; therefore, results from different laboratories can be easily compared. In this study, 55 isolates were classified into 46 types, eight gene groups, and seven clusters by MIRU-VNTR typing. The eight major gene groups, combined with flow epidemiological data, did not identify the means of mutual transmission and direct contact, because we only focused on strains collected in June 2010 to June 2011. Patients of the experimental investigation distributed in a different location of the transmission chain, and were insufficient to reflect the full spread relationship. At the same time, we were unable to collect the strains of previously treated patients; therefore, the infection pattern may be the recurrence of endogenous or recent infection. The analysis indicated that the Beijing family isolates were less likely to be part of a cluster. Future studies using more isolates are required to confirm this hypothesis.

\section{Conclusion}

This is the first report of the genotypes of $M T B$ isolated from patients with pulmonary TB in the Shihezi region of Xinjiang Province, China. We defined 24 MIRUVNTR loci for analyzing the strains. The 55 isolates 
show a high number (16/55) of clusters, and Beijing family strains (47/55) are prevalent in Shihezi region. The drug-resistance rate was high; in particular, two $X D R-T B$ cases were found. It is necessary to strengthen the monitoring, treatment and management for drugresistance $T B$. There was no correlation between drugresistance and the Beijing family genotype.

\section{Competing interests}

The authors declare that they have no competing interests.

\section{Authors' contribution}

LY designed and supervised experiments, and collected the sputa samples; JZ wrote the manuscript, collected the sputa samples, and cultured and identified all strains; JZ, LG Mi, and PZL performed the VNTR genotyping of MTB; YZ. Wang identified the Beijing family strains; HYL and YH performed the drug susceptibility tests; and BL analyzed the data. All authors read and approved the final manuscript.

\section{Acknowledgements and funding}

This study was supported by the "National Natural Science Foundation of China" (30960356) and the "Regional Science Foundation of China" (81160368).

\section{Author details}

'Department of Pathogenic Biology and Immunology, School of Medicine, Shi Hezi University, Shihezi, People's Republic of China. ${ }^{2}$ The First Hospital of Shi Hezi University, Shihezi, People's Republic of China. ${ }^{3}$ National Institute for Communicable Disease Control and Prevention, Chinese Center for Disease Control and Prevention, State Key Laboratory for Infectious Disease Prevention and Control, Beijing, People's Republic of China.

Received: 8 February 2012 Accepted: 14 June 2012

Published: 19 June 2012

\section{References}

1. World Health Organisation: Global tuberculosis control:: WHO report; 2011

2. Frothingham R, Meeker-O'Connell WA: Genetic diversity in the Mycobacterium tuberculosis complex based on variable numbers of tandem DNA repeats. Microbiology 1998, 144(Pt 5):1189-1196.

3. Supply P, Mazars E, Lesjean S, Vincent V, Gicquel B, Locht C: Variable human minisatellite-like regions in the Mycobacterium tuberculosis genome. Mol Microbiol 2000, 36(3):762-771.

4. Alonso-Rodriguez N, Martinez-Lirola M, Herranz M, Sanchez-Benitez M, Barroso P, Bouza E, Garcia DVD: Evaluation of the new advanced 15-loci MIRU-VNTR genotyping tool in Mycobacterium tuberculosis molecular epidemiology studies. BMC Microbiol 2008, 8:34.

5. Christianson S, Wolfe J, Orr P, Karlowsky J, Levett PN, Horsman GB, Thibert L, Tang P, Sharma MK: Evaluation of 24 locus MIRU-VNTR genotyping of Mycobacterium tuberculosis isolates in Canada. Tuberculosis (Edinb) 2010, 90(1):31-38.

6. Maes M, Kremer K, van Soolingen D, Takiff H, de Waard JH: 24-locus MIRUVNTR genotyping is a useful tool to study the molecular epidemiology of tuberculosis among Warao Amerindians in Venezuela. Tuberculosis (Edinb) 2008, 88(5):490-494.

7. Sola C, Filliol I, Legrand E, Lesjean S, Locht C, Supply P, Rastogi N: Genotyping of the Mycobacterium tuberculosis complex using MIRUs: association with VNTR and spoligotyping for molecular epidemiology and evolutionary genetics. Infect Genet Evol 2003, 3(2):125-133.

8. Supply P, Warren RM, Banuls AL, Lesjean S, Van Der Spuy GD, Lewis LA, Tibayrenc M, Van Helden PD, Locht C: Linkage disequilibrium between minisatellite loci supports clonal evolution of Mycobacterium tuberculosis in a high tuberculosis incidence area. Mol Microbiol 2003, 47 (2):529-538.

9. Supply P, Lesjean S, Savine E, Kremer K, van Soolingen D, Locht C: Automated high-throughput genotyping for study of global epidemiology of Mycobacterium tuberculosis based on mycobacterial interspersed repetitive units. J Clin Microbiol 2001, 39(10):3563-3571.
10. Dickman KR, Nabyonga L, Kateete DP, Katabazi FA, Asiimwe BB, Mayanja HK, Okwera A, Whalen C, Joloba ML: Detection of multiple strains of Mycobacterium tuberculosis using MIRU-VNTR in patients with pulmonary tuberculosis in Kampala. Uganda. Bmc Infect Dis 2010, 10:349.

11. Rovina N, Karabela S, Constantoulakis P, Michou V, Konstantinou K, Sgountzos V, Roussos C, Poulakis N: MIRU-VNTR typing of drug-resistant tuberculosis isolates in Greece. Ther Adv Respir Dis 2011, 5(4):229-236.

12. Liu Q, Yang D, Xu W, Wang J, Lv B, Shao Y, Song H, Li G, Dong H, Wan K, et al: Molecular typing of mycobacterium tuberculosis isolates circulating in Jiangsu Province. China. Bmc Infect Dis 2011, 11:288.

13. van Soolingen D, Qian L, de Haas PE, Douglas JT, Traore H, Portaels F, Qing $H Z$, Enkhsaikan D, Nymadawa P, van Embden JD: Predominance of a single genotype of Mycobacterium tuberculosis in countries of east Asia. J Clin Microbiol 1995, 33(12):3234-3238.

14. Rivera-Ordaz A, Gonzaga-Bernachi J, Serafin-Lopez J, Hernandez-Pando R, Van Soolingen D, Estrada-Parra S, Estrada-Garcia I, Chacon-Salinas R: Mycobacterium Tuberculosis Beijing Genotype Induces Differential Cytokine Production by Peripheral Blood Mononuclear Cells of Healthy BCG Vaccinated Individuals. Immunol Invest 2012, 41(2):144-156.

15. Hu Y, Hoffner S, Jiang W, Wang W, Xu B: Extensive transmission of isoniazid resistant $M$. tuberculosis and its association with increased multidrug-resistant TB in two rural counties of eastern China: a molecular epidemiological study. BMC Infect Dis 2010, 10:43.

16. Ma X, Wang H, Deng Y, Liu Z, Xu Y, Pan X, Musser JM, Graviss EA: rpoB Gene mutations and molecular characterization of rifampin-resistant Mycobacterium tuberculosis isolates from Shandong Province, China. J Clin Microbiol 2006, 44(9):3409-3412.

17. Wang J, Liu Y, Zhang $C L$, Ji BY, Zhang LZ, Shao YZ, Jiang SL, Suzuki Y, Nakajima C, Fan CL, et al: Genotypes and characteristics of clustering and drug susceptibility of Mycobacterium tuberculosis isolates collected in Heilongjiang Province, China. J Clin Microbiol 2011, 49(4):1354-1362.

18. Jinghua L, Pourel C, Hauck Y, Xiuqin Z, Zhiguang L, Kanglin W: A new method for the identification of the "Beijing family" strain of Mycobacterium tuberculosis. Chinese Journal of Microbiology and Immunology 2008, 28(2):172-175.

19. Tsolaki AG, Gagneux S, Pym AS, Goguet DLSY, Kreiswirth BN, Van Soolingen D, Small PM: Genomic deletions classify the Beijing/W strains as a distinct genetic lineage of Mycobacterium tuberculosis. J Clin Microbiol 2005, 43 (7):3185-3191.

20. Stavrum R, Valvatne H, Bo TH, Jonassen I, Hinds J, Butcher PD, Grewal HM: Genomic diversity among Beijing and non-Beijing Mycobacterium tuberculosis isolates from Myanmar. PLoS One 2008, 3(4):e1973.

21. Yuan X: The impact of the implementation of the DOTS strategy to TB control in Shihezi region. Endemic Diseases Bulletin 2010, 25(3):44-45. chinese title in the paper

22. Dou HY, Tseng FC, Lin CW, Chang JR, Sun JR, Tsai WS, Lee SY, Su IJ, Lu JJ: Molecular epidemiology and evolutionary genetics of Mycobacterium tuberculosis in Taipei. BMC Infect Dis 2008, 8:170.

23. Huard RC, Lazzarini LC, Butler WR, van Soolingen D, Ho JL: PCR-based method to differentiate the subspecies of the Mycobacterium tuberculosis complex on the basis of genomic deletions. J Clin Microbiol 2003, 41(4):1637-1650.

24. Kanduma E, McHugh TD, Gillespie SH: Molecular methods for Mycobacterium tuberculosis strain typing: a users guide. J Appl Microbiol 2003, 94(5):781-791.

25. Supply P, Allix C, Lesjean S, Cardoso-Oelemann M, Rusch-Gerdes S, Willery E, Savine E, de Haas P, van Deutekom H, Roring $S$, et al: Proposal for standardization of optimized mycobacterial interspersed repetitive unitvariable-number tandem repeat typing of Mycobacterium tuberculosis. J Clin Microbiol 2006, 44(12):4498-4510.

26. Banerjee R, Schecter GF, Flood J, Porco TC: Extensively drug-resistant tuberculosis: new strains, new challenges. Expert Rev Anti Infect Ther 2008, 6(5):713-724.

27. Kremer K, Glynn JR, Lillebaek T, Niemann S, Kurepina NE, Kreiswirth BN, Bifani PJ, van Soolingen D: Definition of the Beijing/W lineage of Mycobacterium tuberculosis on the basis of genetic markers. J Clin Microbiol 2004, 42(9):4040-4049.

28. Wei J, Wei Z, Weidong W, Xiaoming G, Jing Y, Yinuer A, Nianqiang L, Peng $\mathrm{C}$ : The report of WHO drug resistance surveillance on tuberculosis, Xinjiang. The Journal Of The Chinese Antituberculosis Association 2008, 30 (4):307-310. 
29. WHO/IUATLD: Anti-tuberculosis drug resistance in the world: The WHO/IUATLD global project on anti-tuberculosis drug resistance surveillance. WHO Report NO.4. 2008.

30. World Health Organization: Global tuberculosis control and patient care: a ministerial meeting of high M/XDR-TB burden countries. In Beijing, China. 2009.

doi:10.1186/1756-0500-5-309

Cite this article as: Zhang et al:: Genotypes and drug susceptibility of Mycobacterium tuberculosis Isolates in Shihezi, Xinjiang Province, China. BMC Research Notes 2012 5:309.

\section{Submit your next manuscript to BioMed Central} and take full advantage of:

- Convenient online submission

- Thorough peer review

- No space constraints or color figure charges

- Immediate publication on acceptance

- Inclusion in PubMed, CAS, Scopus and Google Scholar

- Research which is freely available for redistribution 